\title{
Construção e Validação Fatorial de uma Medida de Inteligência Emocional
}

\author{
Mirlene Maria Matias Siqueira ${ }^{1}$ \\ Universidade Metodista de São Paulo \\ Nilton Cesar Barbosa \\ Pontifícia Universidade Católica de Campinas \\ Matianny Thyssen Alves \\ Universidade Federal de Uberlândia
}

\begin{abstract}
RESUMO - O estudo teve como objetivo construir e validar uma medida que aferisse cinco habilidades da inteligência emocional. Dentre os 126 itens elaborados para representar as cinco habilidades, 97 deles que apresentaram consistência após análise teórica foram aplicados a uma amostra de 972 sujeitos dos sexos masculino e feminino, com idade média de 22,41 anos. Os dados foram submetidos à analise dos componentes principais e extraídos sete fatores com eigenvalues superiores a 2,0. A rotação dos fatores, através do método ortogonal (varimax), revelou que apenas os cinco primeiros apresentaram agrupamentos de itens teoricamente consistentes com as definições das cinco habilidades da inteligência emocional. O fator 1 cobre o conceito de empatia (14 itens, $\alpha=0,87$ ), o fator 2 o de sociabilidade (13 itens, $\alpha=0,82$ ), o fator 3 representa automotivação (12 itens, $\alpha=0,82$ ), o fator 4 o conceito de autocontrole ( 10 itens, $\alpha=0,84$ ) e o fator 5 a autoconsciência (10 itens, $\alpha=0,78)$. A versão da medida da inteligência emocional, resultante deste estudo, abre perspectivas para futuras pesquisas nacionais sobre o assunto, visto que a MIE possui validade fatorial e fatores com índices de precisão que a indicam para aplicações no âmbito científico.
\end{abstract}

Palavras-chave: inteligência emocional; medida; inteligência.

\section{Construction and Factorial Validation for a Measurement of Emotional Intelligence}

\begin{abstract}
This study was set up to construct and validate a measurement of five skills of emotional intelligence. Among the 126 items elaborated to represent the five skills 97, which demonstrated consistency after theoretical analysis, were applied to a sample of 972 individuals, both male and female, with an average age of 22,41 years. The data were submitted to analysis of the principal components and seven factors were taken with eigenvalues over 2,0. The rotation of these factors, using the orthogonal method (varimax), showed that only the first five factors presented grouping of consistent items with the definitions of the five emotional intelligence skills. Factor 1 covers empathy (14 items, alpha =0,87); factor 2 sociability ( 13 items, alph $a=0,82)$; factor 3 self-motivation ( 12 items, alpha $=0,82$ ); factor 4 self-control (10 items, alpha $=0,84)$, and factor 5 selfconsciousness (10 items, alpha $=0,78)$. The method for measuring emotional intelligence resulting from this study opens possible avenues for future national research on the subject seeing that the measurement is factorially valid and has factors with levels of accuracy which indicate this measure to scientific applications.
\end{abstract}

Key words: emotional intelligence; measure; intelligence.

Inteligência e emoção são dois temas tradicionalmente polêmicos que, mesmo após várias décadas de estudos, ainda despertam interesse e fomentam debates dentro e fora do ambiente acadêmico, existindo, para cada um deles, um vasto campo de teorização e pesquisa.

Desde o século XIX a inteligência humana tornou-se objeto de estudo de cientistas em todo o mundo, quando Herbert Spencer e Francis Galton apontaram para uma capacidade humana geral, distinta de todas as outras (Butcher, 1968/1972). Nessa época, movidos pelo interesse em compreender os processos mentais, neurologistas, psiquiatras,

1 Endereço: R. Manoel Pimenta de Abreu, 116, Bloco A, Ap. 73. CEP: 08710-640 Mogi das Cruzes - SP. E-mail: mmmsiqueira@bol.com.br psicólogos e outros estudiosos se envolveram na investigação científica da inteligência, compreendida, então, como uma capacidade geneticamente determinada. Entretanto, as provas relacionadas a esta proposição teórica eram muito frágeis, pois desprezavam as influências do meio e não efetuavam o correto controle de variáveis, como idade e tempo de aplicação dos testes, para avaliar a inteligência.

Os estudos sobre a inteligência orientaram-se, segundo a visão de Almeida (1996), por dois eixos básicos de definição: um concebendo-a como um fator geral com função integradora das diversas habilidades intelectuais (Binet \& Simon, 1905; Wechsler, 1950) e outro tendo-a como um conjunto de aptidões independentes (Guilford, 1959).

Dentro do primeiro enfoque de inteligência, surgiu em 1905 a primeira escala satisfatória para avaliar diferenças 
intelectuais desenvolvida por Binet e Simon, tendo sido significativamente alterada nos anos subsequentes. Em 1909, Burt publicou os primeiros testes padronizados para crianças tidas como mentalmente deficientes (Butcher, 1968/ 1972). A revisão das escalas Binet-Simon deu origem aos testes de Quociente Intelectual Stanford-Binet, que passaram a levar em consideração, pela primeira vez, a idade cronológica como uma variável importante para se compreender o significado de idade mental (Telford \& Sawrey, 1968/ 1977). O modelo de inteligência que se constituiu com estes primeiros testes de quociente intelectual (Q.I.) estimulou a visão da inteligência como a capacidade de processamento de informações ligadas às habilidades necessárias para o sucesso acadêmico. Isto ocorreu em função de se buscar avaliar os aspectos relacionados às capacidades lógico-matemática e lingüística dos indivíduos, o que proporcionou aos testes de inteligência ampla aceitação nos mais diversos contextos e, em especial, no ambiente escolar, como forma de avaliar os alunos e separá-los de acordo com o nível intelectual que apresentavam.

O segundo eixo de concepção da inteligência orientouse pelo entendimento de que ela seria formada por conjuntos de aptidões independentes. Guilford (1959) elaborou um modelo tridimensional de formato cúbico para representar as categorias de funcionamento intelectual. As três faces do intelecto, segundo o modelo de Guilford, dizem respeito à capacidade de realizar operações, dar origem a produtos e manifestar conteúdos a nível intelectual. As aptidões independentes apontadas por Guilford referem-se à compreensão verbal, fluência verbal, aptidão numérica, rapidez perceptiva, aptidão espacial, memória e raciocínio (Almeida, 1996). Este modelo deu origem a uma bateria de testes multifatoriais muito úteis para escolas e empresas, usados em situações de orientação vocacional e avaliações psicológicas nos mais diversos contextos.

Paralelamente a estes estudos surgiram, nas primeiras décadas do século, as proposições iniciais sobre inteligência social (Broom, 1928, 1930; McClatehy, 1929; Thorndike, 1936) cujo âmbito de interesse eram as habilidades para decodificar informações do contexto social. Em 1966, O'Sullivan e Guilford elaboraram um teste de seis fatores de inteligência social com vistas a representar, através desta medida, a face comportamental do modelo de Guilford (1959; 1967) sobre a estrutura do intelecto. Essa nova modalidade de inteligência foi, posteriormente, revisada por Ford e Tisak (1983) e redefinida como um critério comportamental, representado por habilidades para atingir objetivos relevantes em ambientes sociais específicos. Essas proposições sobre a inteligência social atribuíram maior ênfase ao processamento de informações produzidas pelo meio social do que àquelas de cunho lógico-matemático e lingüístico tão amplamente ressaltadas dentro do contexto acadêmico.

Inicia-se, com a inteligência social, uma tentativa de compreender a inteligência como um fenômeno mais amplo. Dentro deste enfoque, as informações presentes no meio social seriam os elementos principais que alimentariam o processo intelectual. Redireciona-se, desse modo, o eixo central de teorização sobre essas habilidades, saindo-se de um foco que priorizava o processamento de estímulos lógico-matemáticos e linguísticos para uma ênfase nos sinais produzidos pela vida social. A inteligência social, portanto, aparece como uma proposta de compreender as capacidades intelectuais humanas tornando como área de teorização o processo cognitivo de captar e decodificar, com habilidade, informações providas pelo meio social e de apresentar estratégias comportamentais eficazes para atingir objetivos sociais, dentro de um contexto particular. Tal postura teórica é defendida pelos seus proponentes (Keating, 1978; Ford \& Tisak, 1983) como uma complementação ao campo abarcado pela visão tradicional de inteligência, a qual não contempla outras áreas de habilidades relevantes para o processo educacional.

Em 1995, Gardner introduz, no meio cientifico, uma outra abordagem sobre a inteligência, entendida como "capacidade de resolver problemas ou elaborar produtos que são importantes em um determinado ambiente ou comunidade cultural" (Gardner, 1993/1995, p. 21). O autor argumenta que vários conjuntos de habilidades humanas possuem as características necessárias para serem classificadas como inteligências distintas. Configura-se, desta maneira, uma inovadora leitura do intelecto humano denominada teoria das inteligências múltiplas, constituindo uma visão pluralista do intelecto humano, assemelhando-se àquela posição já anteriormente apresentada por Guilford. Na proposição de Gardner, entretanto, a multidimensionalidade da inteligência humana não seria constituída por um conjunto de aptidões independentes como defendia Guilford mas, sim, por inteligências específicas que iriam se manifestar na medida em que existisse a necessidade de criar um produto cultural. Assim sendo, a abordagem das inteligências múltiplas, reconhecendo as capacidades universais da espécie humana, baseia-se num sistema computacional com base neurológica, tendo cada uma das inteligências determinados tipos de informações internas e externas que as desencadeariam. Em sua formulação teórica, Gardner identifica sete tipos de inteligência. Mantendo em sua lista as já tradicionais inteligências lógico-matemática e linguística, ele inclui as inteligências musical, espacial e corporal-cinestésica, ressaltando possíveis influências socioculturais sobre o potencial humano e postula duas outras inteligências de cunho predominantemente sócio-emocional, denominadas inteligência intrapessoal e interpessoal. Esta teorização mescla a visão clássica com as recentes descobertas neurofisiológicas sobre o funcionamento do intelecto. Assim, a grande contribuição de Gardner para o estudo da inteligência é justamente a sedimentação das mais diversas teorias que, há décadas, buscavam ampliar a concepção de inteligência para além das habilidades acadêmicas.

Em um outro âmbito de produção científica, encontramse os estudos relacionados ao tema emoção. No século passado, em 1884, James foi o primeiro a sugerir que as alterações fisiológicas que ocorrem no corpo são a base da experiência emocional e que a percepção destas alterações no organismo é que constituiriam a emoção (Cofer, 1972/1980). 
Essas primeiras formulações e as recentes descobertas no campo da neurologia, como as relatadas por Damásio (1994/1996), tornaram-se fundamentais para ampliar a compreensão das experiências emocionais. Este autor descreve a emoção como alterações orgânicas de nível neural e químico, desencadeadas por estímulos externos ou internos, relacionados a imagens mentais e pensamentos que sofrem influência do contexto social e cultural onde se encontra o indivíduo. $\mathrm{O}$ autor afirma que este processo ocorre sob o controle de estruturas subcorticais e também neocorticais, introduzindo uma relação mais próxima entre emoção e as funções intelectivas do neocortex.

Damásio (1994/1996) também propõe uma classificação dos sentimentos divididos entre os de cunho emocional e os de fundo. Os primeiros são relacionados à leitura de estados emocionais como alegria e tristeza e, os segundos, à leitura da imagem do corpo quando o mesmo não se encontra agitado pelos estados emocionais. Assim, os sentimentos seriam os responsáveis pela cognição do estado visceral, muscular e esquelético do corpo, o que permitiria ao indivíduo efetuar uma leitura do que acontece durante os estados emocionais e de fundo. Desta maneira, a justaposição das imagens do corpo, produzidas pelas emoções, com outras imagens presentes ou despertadas na memória estimulariam atribuição positiva ou negativa a uma determinada situação como sendo, por exemplo, de prazer ou dor.

Damásio (1994/1996) supõe que os estados emocionais necessitam de uma ligação neocortical para serem decodificados e compreendidos pelo indivíduo. Suposições como essas talvez sejam os grandes influenciadores da noção de que existam capacidades intelectivas específicas para a decodificação dos estados emocionais e de todas as informações por eles produzidas.

Isto posto, é possível perceber, tanto na história da inteligência como da emoção, um percurso teórico que gradativamente as aproxima. Observam-se que as proposições teóricas sobre a inteligência paulatinamente passaram a levar em consideração as influências dos estímulos sociais e dos aspectos emocionais, enquanto que a emoção teve sua compreensão teórica cada vez mais relacionada às descobertas sobre os centros neocorticais, responsáveis pelas funções intelectivas.

Os estudos realizados até então apontavam não para uma superposição entre inteligência e emoção, mas, sim, para a compreensão da influência do intelecto na leitura dos estados emocionais e, por outro lado, para a influência das emoções sobre as funções neocorticais. É notório que os conceitos de inteligência e emoção foram estudados em dois blocos separados, mas o aprofundamento científico aproximouos de tal maneira que se tornou evidente a necessidade de uma nova teorização de interdependência entre ambos.

Proposições mais atuais, apresentadas por diversos estudiosos (Damásio, 1994/1996; Goleman, 1995/1996; Lane, Quinlan, Schwartz, Walker \& Zeitlin, 1990; Mayer, DiPaolo \& Salovey, 1990; Mayer \& Geher, 1996; Mayer \& Salovey 1997; Salovey \& Mayer, 1990), têm apontado uma estreita relação entre intelecto e emoção. Esta proposta de interde- pendência tornou-se teoricamente mais organizada quando nos Estados Unidos, no início da década de noventa, Salovey e Mayer apresentaram a concepção de inteligência emocional, definindo-a como a "habilidade de monitorar sentimentos e emoções pessoais e alheias, realizar discriminações entre elas e usar essas informações para guiar os próprios pensamentos e ações" (p. 189).

As proposições de Salovey e Mayer (1990) descrevem os processos mentais relativos à informação emocional, incluindo avaliação e expressão das emoções, sua regulação e utilização. Estes processos, subjacentes à inteligência emocional, teriam início quando informações de natureza afetiva fossem captadas pelo sistema perceptivo.

$\mathrm{O}$ primeiro processo mental diz respeito a avaliação e expressão das emoções pessoais e dos outros. Em relação a si mesmo, o indivíduo baseia-se na observação de informações verbais e não verbais para realizar sua auto-avaliação e escolher a melhor maneira de expressar suas próprias emoções. Em relação ao outro, o indivíduo utilizaria manifestações não verbais de comportamento e de sua empatia pessoal para efetuar a avaliação da expressão de estados emocionais alheios.

O segundo processo mental inclui a regulação das emoções, ou o controle delas, em si mesmo e nos outros. Em si mesmo, permitiria ao indivíduo regular e direcionar seus humores e, na relação com o outro, favoreceria a regulação das relações alheias, ou seja, facilitaria avaliar respostas afetivas externas e escolher o melhor comportamento social a ser emitido durante a interação social.

O terceiro processo constitui a utilização das emoções durante a resolução de problemas cotidianos, ou que requeiram complexidade de raciocínio. Nessas situações, segundo Salovey e Mayer (1990), o uso correto das emoções possibilitaria ao indivíduo elaborar com maior habilidade planos para o futuro, ter pensamentos criativos, ser capaz de dosar e direcionar sua atenção e seu bom humor e, ao mesmo tempo, motivar-se, persistindo, mesmo diante de dificuldades, em seus propósitos anteriormente estabelecidos.

Com o surgimento do conceito de inteligência emocional, criou-se um eixo específico de teorização sobre processamento de informações de natureza emocional, tornando mais amplas as idéias elaboradas por Gardner (1993/1995) quando apresentou as inteligências intrapessoal e interpessoal como duas modalidades de habilidades cognitivas para lidar com conteúdos emocionais. Por outro lado firmou-se, definitivamente, um campo de pesquisa em que as habilidades intelectivas tornaram-se associadas às experiências emocionais.

Em 1996, também nos Estados Unidos, dando sequiência à discussão sobre inteligência emocional, Goleman supõe que ela reja a maior parte das relações e experiências cotidianas e, diferentemente das aptidões acadêmicas, permitiria que as pessoas se saíssem bem em suas atividades cotidianas.

Para Goleman (1995/1996), o conceito de inteligência emocional pauta-se em cinco habilidades básicas e interdependentes denominadas por autoconsciência, automotivação, 
autocontrole, empatia e sociabilidade. As três primeiras referem-se a exames de reações do eu e ao que o indivíduo faz com seus próprios sentimentos, enquanto que as duas últimas voltam-se para fora, em direção aos sentimentos dos outros e às interações sociais.

Dentre as habilidades citadas por Goleman (1995/1996), a autoconsciência pode ser considerada a mais importante, uma vez que ela abre caminho às demais habilidades. A autoconsciência permitiria ao indivíduo perceber, observar, distinguir e nomear seus próprios sentimentos, de modo a se reconhecer e aceitar-se em seus mais diversos estados emocionais. Há na literatura alguns conceitos que fazem fronteira conceitual ou se sobrepõem à definição de autoconsciência. A auto-imagem (Advinícula, 1991; Erthal, 1986) refere-se à percepção do eu e à representação que o indivíduo faz de si mesmo. O autoconceito (Diniz \& Mettel, 1986; Farias \& Carvalho, 1987; Mendonça, 1989; Novaes, 1985; Rodrigues, 1985; Tamayo, 1981) diz respeito à elaboração de um juízo a respeito do eu e à capacidade de fazer distinções a respeito das ocorrências internas. A inteligência intrapessoal, definida por Gardner (1993/1995) como acesso e discriminação entre os sentimentos pessoais constitui também um correlato à habilidade denominada autoconsciência.

A automotivação, segunda habilidade da inteligência emocional, seria a capacidade de elaborar metas para si mesmo, persistindo e entusiasmando-se com os objetivos pessoais. É a capacidade de resistir a quaisquer obstáculos que impeçam a concretização de metas pessoais, envolvendo, no indivíduo que a retém em alto nível, elevado grau de esperança e otimismo. A automotivação assemelha-se aos conceitos de crescimento pessoal e propósitos na vida apresentados por Ryff (1989), que referem-se à elaboração de metas, ao seu avanço, à crença em sua concretização e confiança nos próprios objetivos, bem como abertura a novas experiências.

$\mathrm{O}$ autocontrole, por sua vez, refere-se à capacidade de administrar sentimentos e desenvolver habilidades pessoais para atingir metas anteriormente estipuladas. Um nível elevado de autocontrole levaria o indivíduo a reinterpretar a situação ocorrida e dar-lhe um significado mais positivo, além de possibilitar o adiamento de um impulso momentâneo em prol de uma meta futura. Conceitos como autocontrole e autonomia (Ryff, 1989), percepção de controle pessoal (Barroso, 1975) e locus de controle (Levenson, 1981; Tamayo, 1989) promovem uma compreensão completível a esta habilidade, uma vez que definem-se pelo entendimento dos indivíduos a respeito do que acontece em suas reações e atuações pessoais, bem como de que forma percebem a ocorrência dos fatos que permeiam suas vidas.

Como quarta habilidade da inteligência emocional, a empatia encontra-se como um conceito vastamente estudado (Chlopan, McCain, Carbonell \& Hager, 1985; Santana, 1989). Constitui-se na habilidade de perceber os sentimentos dos outros, através da leitura e compreensão de comportamentos não verbais de comunicação, tais como expressões faciais, tom de voz e postura corporal. Santana, Alta e Bastos (1993) elucida que a empatia possui um componente cognitivo (se o indivíduo sente da mesma maneira como a outra pessoa) e um componente motivacional (se a empatia, quando experienciada, leva o indivíduo a fazer algo). A inteligência interpessoal, proposta por Gardner (1993/1995), abarca o conceito de empatia, pois é definida como "a capacidade de observar e fazer distinções entre os indivíduos e, em particular, entre seus humores, temperamentos, motivações e intenções" (p. 185). Dessa forma, a habilidade denominada por empatia permite que um indivíduo hábil leia as intenções e desejos das pessoas que o cercam, além de possibilitar a este mesmo indivíduo percepção mais acurada dos sentimentos do outro.

Define-se como sociabilidade, quinta habilidade da inteligência emocional, a capacidade de iniciar, aprofundar e manter relações sociais. Ter alta sociabilidade significa ser capaz de substituir sentimentos negativos por outros positivos e disseminá-los naqueles que estão ao redor, tornando os relacionamentos extensos, profundos e verdadeiros. Os conceitos de inteligência social (Ford \& Tisak, 1983), domínio do ambiente (Ryff, 1989), competência social (Del Prette, Del Prette \& Correia, 1992), competência interpessoal (Buhrmester \& Furman, 1988) e habilidades sociais (Hidalgo \& Melo, 1991; Gresham, 1992; Del Prette, Del Prette, Torres \& Pontes, 1998), descritos na literatura, guardam relações conceituais estreitas com a noção de sociabilidade. Assim como a inteligência social definida por Ford e Tisak (1983), as outras definições tratam de comportamentos que um indivíduo emite em um contexto social de modo a aplicar estratégias adequadas e satisfatórias para seus relacionamentos.

As diversas suposições, atuais ou mais antigas, que dão suporte conceitual e teórico à estrutura do recente conceito de inteligência emocional, têm em comum a importância atribuída aos fenômenos psíquicos que se relacionam com a configuração interna do indivíduo como também àqueles que fortalecem uma interdependência equilibrada entre ele e seu meio social. Desse modo, entende-se que as três habilidades denominadas autoconsciência, automotivação e autocontrole seriam as bases de natureza psicológica responsáveis pelo fortalecimento das estruturas internas do indivíduo, enquanto as outras duas, empatia e sociabilidade, constituiriam os componentes psicossociais que assegurariam a sua competência no mundo social.

Assimilando as diversas concepções sobre a inteligência humana aqui apresentadas, entende-se que a inteligência emocional configura-se como um constructo de natureza cognitiva, cujo elemento primordial de sua constituição seriam as informações de cunho emocional produzidas pelo próprio indivíduo quando experiência emoções e as organiza em forma de sentimentos, bem como informações oriundas do meio social fornecidas pela expressão de emoções e sentimentos dos outros.

Tomando como base esta compreensão da inteligência emocional, procurou-se, através desta investigação, construir e validar um instrumento que pudesse aferir, com qualidades psicométricas, as cinco habilidades dela integrantes. 


\section{Metodologia}

\section{Construção da Medida de Inteligência Emocional - MIE Elaboração dos Itens}

Como primeira etapa de construção da Medida de Inteligência Emocional (MIE), realizou-se um levantamento bibliográfico de conceitos correlatos às cinco habilidades emocionais propostas por Goleman (1995/1996). Com base nesta consulta feita à literatura, foi realizada uma restruturação das definições das cinco habilidades da inteligência emocional, com vistas a demarcar o campo conceitual de cada habilidade, tendo cada uma delas recebido uma conotação positiva e outra negativa, como ilustra o Quadro 1.

Após a elaboração das definições, procedeu-se a construção de frases que condiziam com o conceito de cada habilidade, totalizando 126 itens, sendo 19 referentes à autoconsciência, 21 à automotivação, 20 ao autocontrole, 31 à empatia e 35 à sociabilidade. Os itens foram elaborados de tal forma que refletissem ações presentes dos indivíduos (primeira pessoa do indicativo), evitando-se frases que descrevessem crenças ou afetos. As ações constantes dos itens poderiam estar na direção da conotação positiva (itens positivos) ou negativa da habilidade (itens negativos). Com essa configuração, a medida da inteligência emocional que se propõe estaria inicialmente composta por 126 comportamentos distintos que representariam, na sua totalidade, um constructo cognitivo, integrado por cinco diferentes habilidades mentais para lidar com informações de natureza emocional, fossem elas integrantes das experiências emocionais do indivíduo ou presentes no contexto social.

\section{Análise de consistência dos itens}

A lista com 126 itens foi submetida a 15 juízes, sendo 5 psicólogos, 1 filósofo, 2 biólogos e 7 estudantes de psicologia. Foram-lhes apresentadas as definições das habilidades com suas respectivas conotações positivas e negativas e o conjunto de 126 itens. Solicitou-se que julgassem se um dado item representava ou não, em termos conceituais, alguma das cinco habilidades da inteligência emocional. Os juízes avaliaram cada um dos 126 itens colocando, nos parênteses que os antecediam, o número correspondente ao conceito das habilidades que eles julgavam representar.

Com as respostas dos juízes foi possível calcular a frequiência com que eles relacionaram cada frase com as definições das cinco habilidades da inteligência emocional. Para cada um dos itens foi calculado um Índice de Concordância (IC). Na seleção dos itens, para composição da versão piloto da MIE, deveriam ser descartados itens com $I C<80 \%$ e mantidos itens com $I C \geq 80 \%$ (Pasquali, 1996).

Os resultados indicaram que $97(76,98 \%)$ dos 126 itens obtiveram $I C \geq 80 \%$ enquanto que $29(23,02 \%)$ ficaram abaixo do limite estabelecido. Para demonstrar o resultado geral das avaliações dos juízes sobre os 126 itens da MIE, calculou-se o percentual de itens retidos em cada habilidade frente ao total selecionado, como mostra a Tabela 1.

Face a esses resultados, o instrumento piloto ficou composto por 97 itens (positivos e negativos), cuja confiabilidade conceitual foi igual ou superior a 80,0\% na avaliação teórica realizada por quinze juizes.

\section{Validação Fatorial da Medida de Inteligência Emocional - MIE}

Nesta seção, serão descritos os procedimentos, as análises aplicadas aos dados recolhidos, bem como os resultados e discussão relativos à fase do estudo que teve como objeti-

Quadro 1 - Definições das cinco habilidades integrantes da Inteligência Emocional

\section{Autoconsciência:}

Conotação positiva: facilidade de lidar com os próprios sentimentos no que se refere a identificação, nomeação, avaliação, reconhecimento e atenção a estes sentimentos.

Conotação negativa: dificuldade de lidar com os próprios sentimentos no que se refere a identificação, nomeação, avaliação, reconhecimento e atenção a estes sentimentos.

\section{Automotivação:}

Conotação positiva: facilidade de elaborar planos para a própria vida, de modo a criar, acreditar, planejar, persistir e manter situações propícias para a concretização das metas futuras. M anter-se esperançoso e otimista nas diversas fases da vida.

Conotação negativa: dificuldade de elaborar projetos para a vida. Duvidar dos projetos e ser pessimista e desesperançoso.

\section{Autocontrole:}

Conotação positiva: facilidade de administrar os próprios sentimentos, impulsos, pensamentos e comportamentos.

Conotação negativa: dificuldade de administrar os próprios sentimentos, impulsos, pensamentos e comportamentos.

\section{Empatia:}

Conotação positiva: facilidade de identificar os sentimentos, desejos, intenções, problemas, motivos e interesses dos outros, através da leitura e compreensão de comportamentos não verbais de comunicação, tais como, expressões faciais, tom de voz e postura corporal.

Conotação negativa: dificuldade de identificar os sentimentos, desejos, intenções, problemas, motivos e interesses dos outros, através da leitura e compreensão de comportamentos não verbais de comunicação, tais como, expressões faciais, tom de voz e postura corporal.

\section{Sociabilidade:}

Conotação positiva: facilidade de iniciar e preservar as amizades, ser aceito pelas pessoas, valorizar as relações sociais, adaptar-se a situações novas, liderar, coordenar e orientar as ações das outras pessoas.

Conotação negativa: dificuldade de iniciar e preservar amizades, ser pouco aceito pelas pessoas, evitar reuniões sociais, não adaptar-se a situações novas, bem como possuir dificuldades em liderar e coordenar grupos ou ações de outras pessoas.

Tabela 1 - Habilidades da Inteligência Emocional, número e percentual de itens selecionados após análise de consistência

\begin{tabular}{lcc}
\hline $\begin{array}{l}\text { Habilidades da Inteligência } \\
\text { E mocional }\end{array}$ & $\begin{array}{c}\text { Itens selecionados } \\
\text { (IC } \mathbf{~ 8 0 \% ~ ) ~}\end{array}$ & Percentual \\
\hline Autoconsciência & 17 & 17,53 \\
Automotivação & 14 & 14,43 \\
Autocontrole & 17 & 17,53 \\
Empatia & 21 & 21,65 \\
Sociabilidade & 28 & 28,86 \\
Total & 97 & 100 \\
\hline
\end{tabular}


vo analisar a validade fatorial da MIE e aferir a precisão de seus fatores.

\section{Amostra}

O conjunto de 97 itens, resultante das análises preliminares de construção da MIE, foi aplicado a uma amostra de 972 sujeitos, com idade média de 22,41 anos, do sexo masculino $(37,9 \%)$ e feminino $(61,7 \%)$, com grau de escolaridade variando do primeiro grau incompleto $(8,4 \%)$ ao superior completo $(4,1 \%)$, sendo a maioria solteira $(79,8 \%)$.

A amostra foi obtida junto a escolas de primeiro e segundo graus, universidades, empresas públicas e particulares. Em sua composição estão estudantes, professores, funcionários públicos, trabalhadores e pessoas da comunidade, todos residentes em uma cidade situada no Triângulo Mineiro. Parcela significativa da amostra é representada por jovens solteiros, entre 13 e 30 anos, do sexo feminino e que cursavam o terceiro grau.

Uma descrição mais detalhada da amostra encontra-se na Tabela 2 .

\section{Instrumento de Aplicação}

Aos respondentes foi entregue um questionário de quatro páginas contendo, na primeira folha, a apresentação do estudo e dos pesquisadores e nas páginas dois, três e quatro os 97 itens da MIE antecedidos por parênteses. Usando uma escala de quatro pontos ( 1 = nunca; 2 = poucas vezes; $3=$ muitas vezes; 4 = sempre), os respondentes deveriam indicar a frequiência com que emitiam os 97 comportamentos listados. Ao final do instrumento foram recolhidos os dados demográficos da amostra (sexo, idade, estado civil e grau de escolaridade).

Tabela 2 - Dados demográficos da amostra $(n=972)$

\begin{tabular}{|c|c|c|c|}
\hline Variável & Nível & Freqüência & Porcentagem \\
\hline \multirow[t]{3}{*}{ Sexo } & M asculino & 368 & 37,9 \\
\hline & Feminino & 600 & 61,7 \\
\hline & Sem informação & 4 & 0,4 \\
\hline \multirow[t]{5}{*}{ Idade (anos) } & $13-20$ & 470 & 48,4 \\
\hline & $21-30$ & 386 & 39,6 \\
\hline & $31-40$ & 92 & 9,2 \\
\hline & $41-50$ & 20 & 2,0 \\
\hline & $51-59$ & 4 & 0,4 \\
\hline \multirow[t]{3}{*}{ Estado civil } & Solteiro & 777 & 79,9 \\
\hline & Casado & 159 & 16,4 \\
\hline & Outros & 36 & 3,7 \\
\hline \multirow[t]{7}{*}{ Escolaridade } & 10 grau incompleto & 82 & 8,4 \\
\hline & 10 grau completo & 15 & 1,5 \\
\hline & $2^{0}$ grau incompleto & 266 & 27,4 \\
\hline & $2^{0}$ grau completo & 111 & 11,4 \\
\hline & 30 grau incompleto & 457 & 47,1 \\
\hline & 30 grau completo & 40 & 4,1 \\
\hline & Sem informação & 01 & 0,1 \\
\hline
\end{tabular}

\section{Procedimento de Aplicação}

O instrumento foi aplicado, coletivamente, a alunos do primeiro e segundo graus, a estudantes universitários e, individualmente, a professores universitários, funcionários públicos e diversos outros profissionais. A aplicação foi realizada durante o horário de aula ou de trabalho dos sujeitos.

\section{Análise de Dados}

A validade da MIE foi verificada por intermédio de análises fatoriais, através do subprograma Factor do SPSS (Statistical Package for the Social Sciences), empregandose o método dos componentes principais (PC) para extração de fatores, com eigenvalue mínimo igual a 2,0. Para a rotação dos fatores, aplicou-se o método oblíquo (oblimin) e, posteriormente, o ortogonal (varimax), estipulando-se como carga fatorial mínima o valor de 0,40 (positivo ou negativo) para cada um dos itens. Para verificar a precisão dos fatores calculou-se o Alpha de Cronbach, utilizando-se o subprograma Reliability do SPSS.

\section{Resultados}

A análise dos componentes principais apontou a existência de sete agrupamentos principais de itens com eigenvalues superiores a 2,0, explicando $35,3 \%$ da variância total (Tabela 3).

Submetendo-se os sete principais componentes à rotação oblíqua (oblimin), observaram-se correlações fracas (menores que 0,20) entre a maioria dos fatores, exceções feitas ao fator 6 que apresentou correlações positivas mais elevadas com os fatores $1(r=0,35), 5(r=0,20)$ e o fator 7 que correlacionou-se positivamente com os fatores $2(r=$ $0,25)$ e $6(r=0,22)$, conforme demonstra a Tabela 4 . Com

Tabela 3 -Eigenvalues e porcentagem de variância total dos sete principais fatores

\begin{tabular}{ccc}
\hline Fatores & Eigenvalues & $\%$ de variância total \\
\hline 1 & 12,84 & 12,2 \\
2 & 5,12 & 5,3 \\
3 & 4,78 & 4,9 \\
4 & 3,72 & 3,8 \\
5 & 3,18 & 3,3 \\
6 & 2,49 & 2,6 \\
7 & 2,14 & 2,2
\end{tabular}

Tabela 4 - Coeficientes de correlação entre os fatores extraídos através de rotação oblíqua (oblimin)

\begin{tabular}{cccccccc}
\hline Fatores & $\mathbf{1}$ & $\mathbf{2}$ & $\mathbf{3}$ & $\mathbf{4}$ & $\mathbf{5}$ & $\mathbf{6}$ & $\mathbf{7}$ \\
\hline 1 & - & & & & & & \\
2 & 0,08 & - & & & & & \\
3 & 0,07 & $-0,12$ & - & & & & \\
4 & 0,01 & 0,00 & 0,03 & - & & & \\
5 & 0,19 & $-0,14$ & 0,02 & 0,00 & - & & \\
6 & 0,35 & 0,17 & 0,13 & $-0,09$ & 0,20 & - & \\
7 & 0,19 & 0,25 & 0,06 & 0,02 & 0,18 & 0,22 & - \\
\hline
\end{tabular}


Tabela 5 - Denominação e número de itens dos sete fatores após rotação varimax

\begin{tabular}{clc}
\hline Fatores & \multicolumn{1}{c}{ Denominação } & No de itens \\
\hline 1 & Empatia & 14 \\
2 & Sociabilidade & 13 \\
3 & Automotivação & 12 \\
4 & Autocontrole & 10 \\
5 & Autoconsciência & 10 \\
6 & Itens misturados & 8 \\
7 & Itens misturados & 4 \\
\hline
\end{tabular}

base nesses resultados, constatou-se que a melhor estrutura fatorial para os fatores seria uma que os considerasse independentes. Procedeu-se, então, à rotação ortogonal varimax, cujos resultados estão apresentados na Tabela 5 .

A rotação varimax revelou que os cinco primeiros fatores eram extremamente concisos, do ponto de vista teórico, uma vez que cada um deles congregava itens específicos das cinco habilidades da inteligência emocional, com cargas fatoriais maiores do que 0,40 (+ ou -). Os fatores 6 e 7 foram desconsiderados neste estudo porque não apresentavam homogeneidade semântica, uma vez que seus itens integrantes eram oriundos das cinco habilidades, o que impossibilitava sua interpretação psicológica. Essa composição de itens misturados dos fatores 6 e 7 provavelmente seja a responsável pelas correlações mais elevadas existentes entre estes dois fatores e alguns dos demais conforme foi observado quando aplicou-se o método oblíquo para rotação de fatores.

Com esta configuração, resultante da rotação varimax, a MIE ficou constituída por cinco fatores ortogonais representados por 59 itens com cargas fatoriais iguais ou superiores a $0,40(+$ ou -$)$, que se distribuem para compor as cinco habilidades teoricamente propostas neste estudo como integrantes da inteligência emocional.

A revisão da literatura permite identificar duas versões teóricas para o conceito de inteligência emocional. Uma, defendida por Salovey e Mayer (1990), procura articular proposições acerca dos processos mentais que lidam com informações relativas a emoções e sentimentos pessoais e alheios. A outra, apregoada por Goleman (1995/1996), contém formulações distinguindo cinco habilidades que, conforme demonstrado anteriormente neste estudo, se aproximam de diversos conceitos já amplamente estabelecidos na literatura psicológica.

O processo de construção e validação da MIE foi ancorado no pressuposto de ser a inteligência emocional composta por cinco habilidades, conforme proposição de Goleman (1995/1996). Entretanto, a definição de cada habilidade e a construção de itens comportamentais para representá-las tiveram como eixo norteador as concepções de Salovey e Mayer (1990) sobre processos mentais para lidar com informações provenientes de emoções e sentimentos. Assim, ao demonstrar a existência de cinco fatores ortogonais presentes no conjunto de itens integrantes da MIE, este estudo representa um avanço na investigação científica da inteligência emocional, não só porque traz evidências sobre a possibilidade de se avaliar habilidades intelectivas a partir de suas representações comportamentais, como também porque dá suporte às noções de Goleman (1995/1996) de ser a inteligência emocional, enquanto um construto cognitivo, representada por cinco diferentes habilidades. Por outro lado, a metodologia adotada e os resultados obtidos neste estudo representam os primeiros passos na busca de se criar instrumentos psicológicos válidos e precisos para aferir o processamento de informações sobre emoções e sentimentos experimentados ou observados nas interações sociais.

A seguir, serão apresentados os resultados relativos a cada um dos cinco fatores componentes da MIE após rotação varimax e sua interpretação psicológica.

A Tabela 6 apresenta os resultados referentes aos 14 itens do Fator 1, que representa nitidamente o conceito de Empatia, cuja precisão foi de 0,87 . Este fator congrega um conjunto de itens referentes à habilidade de identificar sentimentos, desejos, intenções, problemas e interesses dos outros, através da leitura e compreensão de comportamentos não verbais de comunicação.

Os 13 itens do Fator 2 descrevem a habilidade de iniciar e preservar as amizades, relacionar-se bem, ser aceito pelas pessoas, sentir-se bem entre elas e tratá-las com cordialidade mesmo sendo desconhecidas, constituindo a dimensão da inteligência emocional denominada Sociabilidade (Tabela 7). Esse fator apresentou uma precisão de 0,82.

Tabela 6 - Carga fatorial (CF), descrição e comunalidade $\left(h^{2}\right)$ dos 14 itens integrantes do Fator 1 Empatia.

\begin{tabular}{|c|c|c|c|c|}
\hline \multicolumn{2}{|c|}{ Ordem Item } & \multirow{2}{*}{$\begin{array}{c}\mathbf{C F} \\
0,73\end{array}$} & \multirow{2}{*}{\begin{tabular}{l}
\multicolumn{1}{c}{ Descrição } \\
Identifico com facilidade os sentimentos \\
das pessoas.
\end{tabular}} & \multirow{2}{*}{$\begin{array}{c}\mathbf{h}^{2} \\
0,58\end{array}$} \\
\hline 01 & 54 & & & \\
\hline 02 & 84 & 0,71 & $\begin{array}{l}\text { Sei quando uma pessoa está com } \\
\text { problemas mesmo que ela não fale. }\end{array}$ & 0,54 \\
\hline 03 & 78 & 0,70 & $\begin{array}{l}\text { Reconheço os sentimentos de uma pessoa } \\
\text { através do modo como ela fala. }\end{array}$ & 0,51 \\
\hline 04 & 81 & 0,67 & $\begin{array}{l}\text { Reconheço quando uma pessoa está com } \\
\text { problemas. }\end{array}$ & 0,48 \\
\hline 05 & 31 & 0,65 & $\begin{array}{l}\text { Entendo o que uma pessoa está querendo } \\
\text { mesmo que ela não fale. }\end{array}$ & 0,43 \\
\hline 06 & 53 & 0,64 & $\begin{array}{l}\text { Identifico as intenções de uma pessoa } \\
\text { logo que começa a falar. }\end{array}$ & 0,45 \\
\hline 07 & 74 & 0,61 & $\begin{array}{l}\text { Reconheço como um amigo se sente } \\
\text { através dos seus gestos não verbais. }\end{array}$ & 0,42 \\
\hline 08 & 16 & 0,61 & $\begin{array}{l}\text { Descubro com facilidade o que um amigo } \\
\text { está sentindo. }\end{array}$ & 0,42 \\
\hline 09 & 15 & 0,55 & $\begin{array}{l}\text { Descubro as intenções de uma pessoa pela } \\
\text { forma como ela age. }\end{array}$ & 0,37 \\
\hline 10 & 58 & 0,54 & $\begin{array}{l}\text { Identifico quando al guém que conheço } \\
\text { está com problemas. }\end{array}$ & 0,38 \\
\hline 11 & 80 & 0,53 & $\begin{array}{l}\text { Reconheço quando uma pessoa está bem } \\
\text { ou não pelo seu tom de voz. }\end{array}$ & 0,31 \\
\hline 12 & 83 & 0,50 & $\begin{array}{l}\text { Sei quando um amigo precisa de minha } \\
\text { ajuda. }\end{array}$ & 0,38 \\
\hline 13 & 07 & 0,48 & $\begin{array}{l}\text { Consigo nomear os sentimentos das } \\
\text { pessoas mais próximas. }\end{array}$ & 0,33 \\
\hline 14 & 56 & 0,47 & $\begin{array}{l}\text { I dentifico os interesses das pessoas com } \\
\text { quem convivo. }\end{array}$ & 0,30 \\
\hline Eigenve & & & & 12,84 \\
\hline$\%$ de V & riâncic & a Total & & 12,20 \\
\hline Alpha & & & & 0,87 \\
\hline
\end{tabular}


Tabela 7 - Carga fatorial (CF), descrição e comunalidade $\left(h^{2}\right)$ dos 13 itens integrantes do Fator 2 Sociabilidade

\begin{tabular}{|c|c|c|c|c|}
\hline \multicolumn{2}{|c|}{ Ordem Item } & \multirow{2}{*}{$\begin{array}{l}\text { CF } \\
0,70\end{array}$} & \multirow{2}{*}{$\begin{array}{l}\text { Descrição } \\
\text { Tenho muitos amigos. }\end{array}$} & \multirow{2}{*}{$\begin{array}{r}\mathbf{h}^{2} \\
0,55\end{array}$} \\
\hline 1 & 92 & & & \\
\hline 2 & 04 & 0,68 & $\begin{array}{l}\text { Aumento o número de pessoas do meu } \\
\text { ciclo de amizades. }\end{array}$ & 0,50 \\
\hline 3 & 67 & $-0,64$ & Prefiro ter poucos amigos. & 0,46 \\
\hline 4 & 82 & 0,52 & Relaciono-me bem com qualquer pessoa. & 0,36 \\
\hline 5 & 96 & 0,51 & $\begin{array}{l}\text { Trato al guém que acabei de conhecer } \\
\text { como se fôssemos vel hos amigos. }\end{array}$ & 0,37 \\
\hline 6 & 39 & 0,51 & $\begin{array}{l}\text { Faço com que as pessoas se sintam bem } \\
\text { ao meu lado. }\end{array}$ & 0,38 \\
\hline 7 & 66 & $-0,46$ & $\begin{array}{l}\text { Prefiro ficar calado a conversar com } \\
\text { pessoas desconhecidas. }\end{array}$ & 0,43 \\
\hline 8 & 11 & 0,45 & $\begin{array}{l}\text { Converso animadamente com um } \\
\text { desconhecido. }\end{array}$ & 0,37 \\
\hline 9 & 12 & 0,45 & $\begin{array}{l}\text { Deixo as pessoas à vontade perto de } \\
\text { mim. }\end{array}$ & 0,27 \\
\hline 10 & 23 & 0,45 & $\begin{array}{l}\text { Encontro al guém conhecido na maioria } \\
\text { dos lugares aonde vou. }\end{array}$ & 0,26 \\
\hline 11 & 68 & $-0,44$ & Prefiro trabalhar sozinho. & 0,28 \\
\hline 12 & 06 & 0,42 & Consigo animar qualquer ambiente. & 0,32 \\
\hline 13 & 46 & 0,41 & $\begin{array}{l}\text { Fico à vontade entre pessoas recém } \\
\text { conhecidas. }\end{array}$ & 0,41 \\
\hline \multicolumn{2}{|c|}{ Eigenvalue } & & & 5,12 \\
\hline \multicolumn{3}{|c|}{ \% de Variância Total } & & 5,30 \\
\hline \multicolumn{2}{|c|}{ Alpha } & & & 0,82 \\
\hline
\end{tabular}

Tabela 8 - Carga Fatorial (CF), descrição e comunalidade $\left(h^{2}\right)$ dos 12 itens integrantes do Fator 3 Automotivação

\begin{tabular}{|c|c|c|c|c|}
\hline \multicolumn{2}{|c|}{ Ordem Item } & \multirow{2}{*}{$\begin{array}{l}\mathbf{C F} \\
0,62\end{array}$} & \multirow{2}{*}{\begin{tabular}{l}
\multicolumn{1}{c}{ Descrição } \\
Persisto em meus objetivos mesmo \\
diante de fortes obstáculos.
\end{tabular}} & \multirow{2}{*}{$\frac{\mathbf{h}^{\mathbf{\gamma}}}{0,45}$} \\
\hline 1 & 63 & & & \\
\hline 2 & 29 & 0,57 & $\begin{array}{l}\text { Enfrento qual quer obstáculo para } \\
\text { conseguir o que quero na vida. }\end{array}$ & 0,40 \\
\hline 3 & 51 & 0,54 & $\begin{array}{l}\text { Fixo minha atenção nos planos que } \\
\text { selecionei para a minha vida. }\end{array}$ & 0,37 \\
\hline 4 & 02 & 0,53 & $\begin{array}{l}\text { Ajo com otimismo em relação aos meus } \\
\text { projetos. }\end{array}$ & 0,35 \\
\hline 5 & 60 & 0,51 & $\begin{array}{l}\text { Oriento minhas ações no presente pelos } \\
\text { planos que fiz para o futuro. }\end{array}$ & 0,37 \\
\hline 6 & 22 & 0,48 & $\begin{array}{l}\text { Elaboro com entusiasmo um projeto } \\
\text { pessoal. }\end{array}$ & 0,37 \\
\hline 7 & 64 & 0,46 & $\begin{array}{l}\text { Planejo situações para concretização de } \\
\text { meus objetivos. }\end{array}$ & 0,34 \\
\hline 8 & 21 & $-0,46$ & $\begin{array}{l}\text { Duvido da realização das minhas metas } \\
\text { futuras. }\end{array}$ & 0,35 \\
\hline 9 & 90 & 0,45 & Tenho entusiasmo com a minha vida. & 0,37 \\
\hline 10 & 03 & 0,44 & $\begin{array}{l}\text { A canço os objetivos que estipulo para a } \\
\text { minha vida. }\end{array}$ & 0,29 \\
\hline 11 & 13 & $-0,42$ & $\begin{array}{l}\text { Deixo de realizar projetos importantes } \\
\text { para a minha vida. }\end{array}$ & 0,30 \\
\hline 12 & 19 & 0,41 & $\begin{array}{l}\text { Dirijo meus sentimentos para agir com } \\
\text { sabedoria. }\end{array}$ & 0,32 \\
\hline \multicolumn{2}{|c|}{ Eigenvalue } & & & 4,78 \\
\hline \multicolumn{3}{|c|}{ \% de Variância Total } & & 4,90 \\
\hline \multicolumn{2}{|c|}{ Alpha } & & & 0,82 \\
\hline
\end{tabular}

$\mathrm{O}$ conjunto de 12 itens do Fator 3 refere-se à persistência, coragem, força, otimismo e entusiasmo com que o indivíduo maneja objetivos e planos para sua vida. Ele constitui
Tabela 9 - Carga fatorial (CF), descrição e comunalidade $\left(h^{2}\right)$ dos 10 itens integrantes do Fato 4 Autocontrole

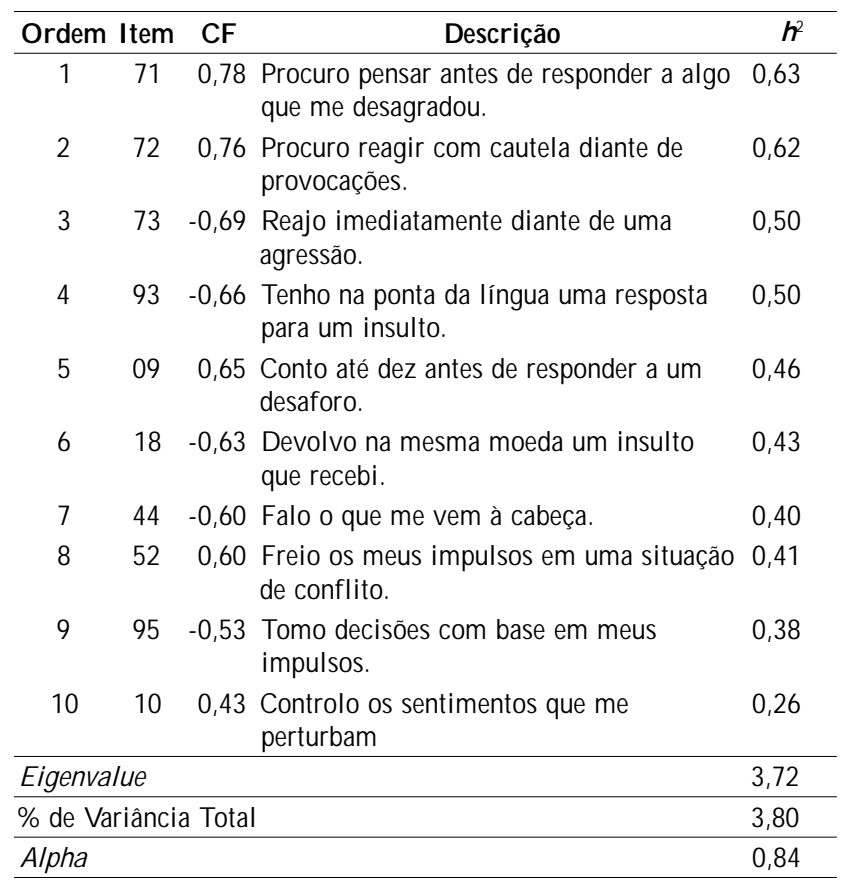

Tabela 10 - Carga fatorial (CF), descrição e comunalidade $\left(h^{2}\right)$ dos 10 itens integrantes do Fator 5 Autoconsciência

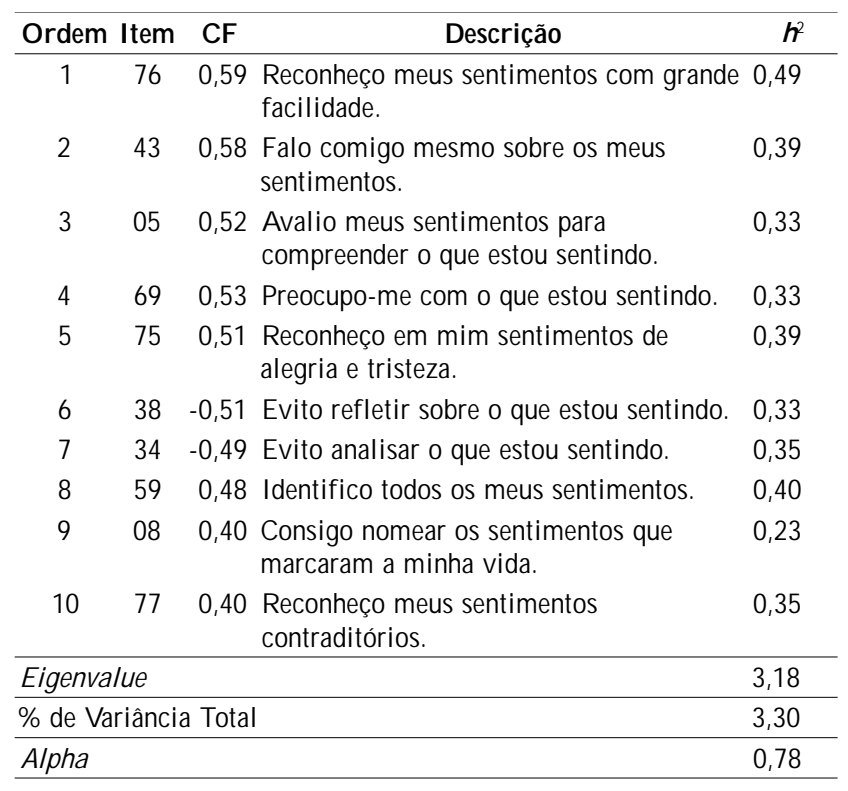

a habilidade denominada Automotivação da inteligência emocional com índice de precisão de 0,82 (Tabela 8).

O conjunto de dez itens do Fator 4 reflete a capacidade de ponderação, cautela e controle com que o indivíduo age frente a fatos desagradáveis, a provocações, agressões, desaforos, insultos, conflitos, sentimentos perturbadores e impulsos. Ele representa, claramente, a habilidade da inteligência emocional denominada Autocontrole, com índice de precisão de 0,84 (Tabela 9).

A Tabela 10 contém os dez itens referentes ao Fator 5 denominado Autoconsciência. Esta habilidade da inteligên- 
cia emocional está representada por itens que descrevem ações introspectivas de reconhecer, avaliar, refletir, nomear e identificar os próprios sentimentos, tendo apresentado precisão de 0,78 .

\section{Aplicação e Apuração da MIE}

A aplicação da MIE poderá ser realizada individual ou coletivamente, respeitando-se as instruções e formato de respostas validados neste estudo.

A melhor estruturação dos itens em fatores ortogonais permite aplicar isoladamente os subconjuntos de itens dos respectivos fatores para obtenção de cinco escores específi$\cos$, referentes a cada uma das cinco habilidades da inteligência emocional. A obtenção desses escores deverá ser feita somando-se os valores assinalados pelos respondentes na escala de respostas para cada item de um dado fator e, em seguida, dividindo-se o somatório pelo número de itens do fator.

\section{Conclusões}

Apesar da superposição conceitual observada entre alguns conceitos já integrantes da literatura psicológica e as definições das cinco habilidades da inteligência emocional, apresentadas recentemente por Goleman (1995/1996), foi possível elaborar concepções objetivas para as mesmas e representá-las através de itens comportamentais específicos, delimitando, assim, o campo conceitual de cada uma. Este procedimento garantiu que todos os itens selecionados para integrar a versão inicial da MIE detivessem Índices de Concordância extremamente favoráveis $(I C \geq 0,80 \%)$, após análise teórica realizada por 15 juízes. A análise teórica permitiu, portanto, que o conjunto de itens usado para o estudo de validação fatorial da Medida de Inteligência Emocional fosse expurgado de confusão conceitual e, conseqüentemente, representasse, de forma bastante apurada, as definições das cinco habilidades da inteligência emocional elaboradas para este estudo.

As análises aplicadas durante a validação fatorial da MIE confirmaram que os 59 itens selecionados para compor sua forma final configuram-se em cinco componentes principais, conceitualmente afinados com as definições teóricas das cinco habilidades inicialmente propostas.

Os dados empíricos relatados neste estudo parecem indicar que os cinco fatores integrantes da MIE sejam subescalas independentes, formadas por fatores ortogonais, detentores de validade conceitual e fatorial, além de possuírem índices de precisão satisfatórios para fins de pesquisa, visto que todos os seus cinco fatores principais apresentaram índices de precisão (Alpha de Crombach) situados entre 0,78 e 0,87 .

Parece relevante, entretanto, ressaltar algumas limitações referentes à Medida da Inteligência Emocional resultante deste estudo. Embora fatorialmente válida e com índices de precisão satisfatórios para aplicações científicas, entende-se que a MIE seja uma medida passível de sofrer influência de direcionamento das respostas por parte dos seus respondentes, por tratar-se de um instrumento que solicita auto-relato de comportamentos e porque a maioria dos seus itens positivos parece possuir conotação de desejabilidade social. Este aspecto merece atenção em estudos posteriores.

Para ampliar os resultados aqui relatados acerca da Medida de Inteligência Emocional, sugerem-se também estudos que busquem elevar os índices de precisão de seus fatores, especialmente para o fator 5 , referente à Autoconsciência, que deteve valor de confiabilidade inferior a 0,80 . Fazem-se necessárias, também, investigações para apurar a validade discriminante dos cinco fatores integrantes da MIE em relação às medidas dos conceitos correlatos às cinco habilidades da inteligência emocional já constantes da literatura psicológica. Adicionalmente, torna-se indispensável a aplicação da MIE a amostras de respondentes com características demográficas distintas, para proceder estudos acerca de sua padronização.

\section{Referências}

Advinícula, I.F. (1991). Tendência atualizante e vontade de potência: um paralelo entre Rogers e Nietzsche. Psicologia: Teoria e Pesquisa, 7, 201-14.

Almeida, L.S. (1996). Considerações em torno da medida da inteligência. Em L. Pasquali (Org.), Teoria e métodos de medida em ciências do comportamento (pp. 199-223). Brasília: UnB/ INEP.

Barroso, C.L. (1975). Análise das dimensões de percepção de controle pessoal: desenvolvimento de uma escala. Arquivos Brasileiros de Psicologia Aplicada, 27, 16-29.

Binet, A. \& Simon, T. (1905). Méthodes nouvelles pour le diagnostic du niveau intellectuel des anormaux. L'Année Psychologique, 11, 191-244.

Broom, M.E. (1928). A note on the validity of a test of social intelligence. Journal of Applied Psychology, 12, 426-428.

Broom, M.E. (1930). A further study of the validity of a test of social intelligence. Journal of Educational Research, 22, 403405.

Buhrmester, D. \& Furman, W. (1988). Five domains of interpersonal competence in peer relationships. Journal of Personality and Social Psychology, 55, 991-1008.

Butcher, J. (1972). A inteligência humana. (D.M. Leite, Trad.) São Paulo: Perspectiva. (Trabalho original publicado em 1968)

Chlopan, B.E., McCain, M.L., Carbonell, J.L. \& Hager, R.L. (1985). Empathy: Review of available measures. Journal of Personality and Social Psychology, 48, 635-53.

Cofer, C.N. (1980). Motivação e emoção. ( B. Jablonski \& R. Fucs, Trads.) Rio de Janeiro: Interamericana. (Trabalho original publicado em 1972)

Damásio, A.R. (1996). O erro de Descartes: emoção, razão e cérebro humano. (D. Vicente \& Segurado, Trads.) São Paulo: Companhia das Letras. (Trabalho original publicado em 1994)

Del Prette, A., Del Prette, Z.A.P., Torres, A.C. \& Pontes, A.C. (1998). Efeitos de uma intervenção sobre a topografia das habilidades 
sociais dos professores. Psicologia Escolar e Educacional, 2(1), 11-22.

Del Prette, Z.A.P., Del Prette, A. \& Correia, M.F.B. (1992). Competência social: um estudo comparativo entre alunos de Psicologia, Serviço Social e Engenharia Mecânica. Psicólogo escolar: identidade e perspectivas, pp. 382-384.

Diniz, M.D. \& Mettel, T.B. (1986). Persistência na tarefa: uma contribuição ao estudo do autoconceito. Arquivos Brasileiros de Psicologia, 38, 110-132.

Erthal, T.C. (1986). Auto-imagem: possibilidades e limitações da mudança. Arquivos Brasileiros de Psicologia, 38, 39-46.

Farias, F.R. \& Carvalho, S.A.C. (1987). Escala de auto-avaliação sobre esquema corporal. Arquivos Brasileiros de Psicologia, 39, 23-35.

Ford, M.E. \& Tisak, M.S. (1983). A further search for social intelligence. Journal of Educational Psychology, 75, 196-206.

Gardner, H. (1995). Inteligências múltiplas: a teoria na prática. (M.A.V. Veronese, Trad.) Porto Alegre: Artes Médicas. (Trabalho original publicado em 1993)

Goleman, D. (1996). Inteligência emocional. (M. Santarrita, Trad.) Rio de Janeiro: Objetiva. (Trabalho original publicado em 1995)

Gresham, F.M. (1992). Social skills and learning disabilities: Causal, concomitant, or correlation? School Psychology Review, 21, 343-60.

Guilford, J.P. (1959). Three faces of intellect. American Psychologist, 14, 469-479.

Guilford, J.P. (1967). The nature of intelligence. New York: McGrawHill.

Hidalgo, C.L. \& Melo, N.A. (1991). Comunicacion interpersonal Santiago do Chile. Ediciones Universidade Católica.

Keating, D.P. (1978). A search of social intelligence. Journal of Educational Psychology, 70, 218 - 233.

Lane, R.D., Quinlan, D.M., Schwartz, G.E., Walker, P.A. \& Zeitlin, S.B. (1990). The levels of emotional awareness scale: A cognitive-developmental measure of emotion. Journal of Personality Assessment, 55(1-2), 124-134.

Levenson, H. (1981). Differentiating among internality, powerfull others, and chance. H.M. Lefcourt (Org.), Research with the locus of control construct. New York: Academic Press.

Mayer, J.D. \& Geher, G. (1996). Emotional intelligence and the identification of emotion. Intelligence, 22, 89-113.

Mayer, J.D. \& Salovey, P. (1997). What is emotional intelligence? Em P. Salovey \& D.J. Sluyter (Orgs.), Emotional development and emotional intelligence: Educational implications (pp. 331), New York: Basic Books.
Mayer, J.D., DiPaolo, M. \& Salovey, P. (1990). Perceiving affective content in ambiguous visual stimuli: A component of emotional intelligence. Journal of Personality Assessment, 54(3/ 4), 772-781.

McClatehy, V.R. (1929). A theorical and statistical critique of the concept of social intelligence and of attempts to measure such a process. Journal of Abnormal and Social Psychology, 24, 217220.

Mendonça, E.M. (1989). Autoconceito e percepção de normas de ética pública. Arquivos Brasileiros de Psicologia, 41, 34-38.

Novaes, M.H. (1985). Autoconceito-um sistema multidimensional hierárquico e sua avaliação em adolescentes. Arquivos Brasileiros de Psicologia, 37, 27-43.

O'Sullivan, M. \& Guilford, J.P. (1966). Six factor tests of social intelligence: Manual of instructions and interpretations. Beverly Hills: Sheridan Psychological Services.

Pasquali, L. (1996). Medida psicométrica. Em L. Pasquali (Org.), Teoria e métodos de medida em ciências do comportamento (pp. 73-116). Brasília: UnB/INEP.

Rodrigues, A. (1985). Padronização da versão em português da Escala de Autoconceito de Janis e Field revisada por Eagly. Psicologia: Teoria e Pesquisa, 1, 158-167.

Ryff, C.D. (1989). Happiness is everything, or it? Exploration on the meaning of psychological well-being. Journal of Personality and Social Psychology, 57, 1069-1081.

Salovey, P. \& Mayer, J.D. (1990). Emotional intelligence. Imagination, Cognition, and Personality, 9, 185-211.

Santana, R.P., Alta, E. \& Bastos, M.F. (1993). Um estudo naturalístico de comportamentos empáticos em pré-escolares. Psicologia: Teoria e Pesquisa, 9, 575-586.

Tamayo, A. (1981). EFA: escala fatorial de autoconceito. Arquivos Brasileiros de Psicologia, 33, 87-102.

Tamayo, A. (1989). Validade fatorial da escala de Levinson de locus de controle. Psicologia: Teoria e Pesquisa, 5, 111-122.

Telford, C.W. \& Sawrey, J.M. (1977). Psicologia: uma introdução aos princípios fundamentais do comportamento. (O.M. Cajado, Trad.) São Paulo: Cultrix. (Trabalho original publicado em 1968)

Thorndike, R.L. (1936). Factor analysis of social and abstract intelligence. Journal of Educational Psychology, 27, 231-233.

Wechsler, D. (1950). Cognitive, conative, and non-intellective intelligence. American Psychologist, 15, 78-83. 